\title{
VERBOS DE CONSTRUCCIÓN PRONOMINAL ALTERNANTE EN PORTUGUÉS Y ESPAÑOL: ESQUEMAS DE INTRANSITIVIDAD O TRANSITIVIDAD INDIRECTA
}

\author{
Shirley de Sousa Pereira*
}

\begin{abstract}
Resumen: En el marco de los esquemas de intransitividad y transitividad indirecta (preposicional), este trabajo se limita a describir algunos ejemplos de verbos que alternan entre una construcción pronominal y otra no pronominal en portugués al contrario del uso pronominal único que presentan en español. Este tipo de alternancia diatética arranca del empleo de la voz media que en latín asumía distintos valores o acepciones y que explica el hecho de que una buena parte de verbos transitivos se construyan necesariamente como pronominales cuando se emplean como intransitivos.
\end{abstract}

Palabras clave: Intransitividad; transitividad indirecta; voz media; portugués; español.

Abstract: Under the sign of intransitivity and indirect transitivity (prepositional) models, this paper purposes only to describe a few examples of verbs that transit from a pronominal construction to a non-pronominal one in Portuguese, in opposition to that exclusive pronominal type, as it occurs in Spanish. This kind of diatectic alternation derives from the use of the middle voice which, in Latin, assumed distinct values or meanings, what explains why a number of transitive verbs are necessarily constructed as pronominal ones when they are applied as intransitive verbs.

Keywords: Intransitivity; indirect transitivity; middle voice; Portuguese; Spanish.

* Universidade Federal do Rio Grande do Norte. 


\section{Introducción}

La pronominalización o el uso de la voz media de verbos que presentan una estructura intransitiva (INT) o transitiva indirecta (TIND) es un fenómeno natural y frecuente tanto en portugués como en español: ${ }^{1}$ rir(-se) / reír(se), ir(se), baixar(-se) / bajar(se), combinar(se) con, confiar(se) en. Es decir, en ambas lenguas se utilizan verbos transitivos e intransitivos de forma pronominal para expresar las distintas manifestaciones de la llamada voz media, a semejanza de lo que pasaba en latín.

El latín poseía desinencias personales en el infectum para la voz "medio-pasiva" cuyas formas acababan en -or, en oposición a la voz "activa" cuyas formas acababan en $-o$. La voz medio-pasiva, al contrario de la voz activa, expresaba de manera explícita el rasgo de afección del sujeto, su grado de mayor o menor implicación en el proceso expresado por el verbo. De ese modo, la voz media en latín se utilizaba para expresar, entre otros valores, el significado de "afección interna" con sujeto no agente para verbos de movimiento: ferri ("dirigirse hacia"), moveri ("moverse"), verti ("volverse"), volvi ("revolcarse"), colligi ("reunirse"), etc; verbos con valor semántico inherente o adquirido de afección para empleo tanto "transitivo" como "intransitivo": excruciari ("atormentarse"), dedi ("rendirse", "hacerse"), purgari ("purgar", "justificarse"), morior ("morir"), uideri ("parecer"), frangi ("romperse"), minui ("disminuir"), mutari ("cambiar"), etc; la mayoría de los verbos deponentes (sin vOz activa): imitari, irasci, laetari, reminisci, obliuisci, loqui, fari, populari, etc.

Con el paso del tiempo, las desinencias propias de la medio-pasiva latina no fueron suficientes para evitar ciertas ambigüedades de sentido en frases como Puer induitur, que podía

\footnotetext{
${ }^{1}$ Este tipo de alternancia constituye uno de los asuntos abordados en mi tesis doctoral intitulada Estudio contrastivo del régimen verbal en el portugués y el español peninsular (PEREIRA, 2007).
} 
significar tanto "el niño se viste" como también "el niño es vestido" (por su madre, por ejemplo). Como solución a ello se empezó a utilizar una perífrasis de un verbo activo combinado con el pronombre personal oblicuo referente al sujeto: Puer se lavat manus ("el niño se lava las manos").

Las lenguas románicas como el portugués y el español heredaron la construcción verbo-pronominal de la voz mediopasiva latina así como sus acepciones. En ambas lenguas, la perífrasis de $s e+$ verbo activo viene a sustituir la pasiva latina cuando esta asume los valores de la denominada voz media, en contraposición a la voz pasiva que pasó a expresarse mediante la locución perifrástica de verbo ser + participio. Dicho procedimiento de pronominalización, al principio, no muy frecuente, se extendió luego a todos los verbos; de hecho, observa Martín Zorraquino (1979, p. 19, n. 1) que desde los textos más antiguos como las comedias de Plauto,

el pronombre se presenta, en latín, con sujetos animados, preferentemente de persona, y verbos susceptibles de entrar en giro transitivo, para expresar nociones como la reflexividad (miles se lavat), la llamada voz media (o medialidad) de interés (quo tu teagis?) y la reciprocidad (cum se ibi laete invitarent...). Con verbos intransitivos y sujetos tanto de persona como de cosa, el uso del pronombre adquiere especial desarrollo e incremento en los períodos de decadencia, sobre todo, al parecer, en la lengua hablada. (MARTÍN ZORRAQUINO, 1979, p. 19, n. 1)

Para el objeto de estudio que nos ocupa en este trabajo, se parte de la concepción de que los esquemas de construcción pronominal que asumen determinados verbos en portugués y español son equivalentes a formas de expresión que sirven para reflejar diferentes contenidos o manifestaciones de la voz media. Como marco teórico central se sigue la propuesta de Pena (1982) para la caracterización de la voz media en español, la cual se basa fundamentalmente en criterios semánticos a partir de las 
relaciones establecidas entre el sujeto y el verbo. Al contrario de otras posturas más tradicionales, la diátesis o voz media no constituye para Pena un "accidente gramatical" o "categoría verbal", sino que funciona como una "categoría gramatical" que viene expresada en la propia flexión del significante verbal caracterizando la base de predicación nuclear como un todo. Tomando como base el contenido que la categoría "voz" denotaba en latín y en griego, propone un sistema bipartito al que denomina "oposición binaria restrictiva o inclusiva" entre voz activa y voz media, donde le corresponde a cada categoría los rasgos semánticos de - afección y de +afección, respectivamente:

En español, como en latín y en griego, la información de la categoría gira en torno a la noción de "afección" o "participación" del término "sujeto gramatical" en el proceso expresado por el verbo, y las opciones o modalidades que permite son dos: voz activa y voz media. Ambas opciones guardan entre sí una relación de oposición privativa o restrictiva: la voz media, término marcado de la oposición, indica que el sujeto se encuentra afectado por el proceso; la voz activa, término no marcado, bien indica que el sujeto no se encuentra afectado por el proceso, bien - caso de neutralización - no informa acerca de si está afectado o no. (PENA, 1982, p. 247-248)

De acuerdo con eso, la voz media se alza como término positivo de una oposición categorial opuesto a la voz activa (término negativo) y comprende otras opciones o acepciones: reflexivo-recíproca, interna y pasiva. Los diferentes contenidos de la voz media dan lugar a diferentes estructuras sintácticas que revelan el grado de afectación del sujeto en relación al proceso expresado por el verbo (PENA, 1982, p. 234).

Por otra parte, la voz media en portugués y en español, al igual que la voz medio-pasiva latina, expresa el carácter "afectado" del sujeto y asume, del mismo modo, el valor de "afección interna" en oraciones con sujeto explícito, salvo en casos de elisión: 
João calou-se / Juan se calló

João arrependeu-se disso / Juan se arrepintió de eso João barbeou-se /Juan se afeitó en la barbería

\section{Esquemas de transitividad indirecta (TIND) $e$ intransitividad (INT)}

En español, se constatan casos en los que, a diferencia del portugués, la pronominalización es posible pero no así el fenómeno contrario, esto es, la intransitivización o transitivización indirecta de verbos pronominales. Así, algunos verbos en español únicamente pueden asumir una estructura transitiva indirecta $o$ intransitiva en determinadas acepciones bajo el giro pronominal, mientras que en portugués dichas estructuras pueden ocurrir indistintamente de forma no-pronominal y pronominal.

Se sabe que existe una relación muy estrecha entre la transitividad e intransitividad, en la medida que muchos verbos inicialmente transitivos pueden emplearse como intransitivos $y$ viceversa. Pues bien, del mismo modo, los procesos de transitivización e intransitivización están íntimamente ligados a la pronominalización. Por ello, la gran mayoría de los verbos transitivos en portugués y en español pueden pronominalizarse, esto es, conjugarse en voz media, pasando a ser el sujeto la entidad afectada por la acción, cambiando normalmente de un esquema transitivo a otro intransitivo pronominal (PIN) o transitivo indirecto pronominal (PTIND), bien en acepción reflexiva, bien en acepción de "afección interna”. Así compárese:

Alguém abriu a porta / A porta abriu-se.

Alguien abrió la puerta / Se abrió la puerta.

O menino rompeu o jarro / O jarro rompeu-se.

El niño rompió el jarrón / El jarrón se rompió.

O animal feriu o caçador / O caçador feriu-se.

El animal birió al cazador / El cazador se hirió. 
O rapaz beija a namorada / Os namorados se beijam.

El chico besa a la novia / Los novios se besan.

O mercado abastece a cidade / A cidade se abastece de víveres.

El mercado abastece la ciudad / La ciudad se abastece de víveres.

En los ejemplos arriba se constata que la presencia del índice de voz media se es condición necesaria para que los verbos de estructura transitiva pasen a formar, en este caso, una estructura intransitiva o transitiva indirecta (HERNÁNDEZ, 1986, p. 168).

De acuerdo con esto, la mayoría de los verbos transitivos en español se convierte necesariamente en pronominales al adoptar una estructura intransitiva o transitiva indirecta, pues de este modo se mantiene la "extensión" de la acción verbal hacia algún afectado, que en este caso, pasa a ser el "sujeto". En contraste con este uso muy latino de la voz media en español, en portugués el uso intransitivo de estos verbos no siempre está condicionado al empleo de la forma pronominal, pudiendo construirse con o sin ella, conforme comprobaremos a continuación.

\subsection{Portugués TIND y PRON $>$ español PRON}

En lo que atañe a los verbos que normalmente exigen complementación prepositiva, se observan casos de alternancia entre el complemento preposicional en construcción no pronominal y pronominal en portugués, frente a la complementación preposicional de forma pronominal única en español. Así por ejemplo, los verbos cruzar y remontar poseen en portugués y en castellano acepciones en régimen transitivo directo, pero, al construirse en estructura transitiva indirecta, ambos verbos se pronominalizan en español, lo no ocurre necesariamente en portugués:

\section{Cruzar}

Pasar una persona o cosa al lado de otra que marcha en sentido opuesto. Portugués:

TIND: $\quad$ Alice vem pelo corredor do bospital com Eduarda e Inocência e cruza com Velbo Gui. (FOLHAONLINE, Ilustrada, 06/03/2006)

PRON: $\quad$ Cruzaram-se com um bando de rapazes. 
Español:

PRON: $\quad$ Unos muchachos con camisa negra y cabello amelenado que se cruzaron con ella la miraron con insolencia. (ALÓS, Hogueras, p. 212 apud SECO ET AL, 1999)

\section{Remontar}

1. Subir, ir hacia arriba, particularmente las aves, los aviones, etc.

2. Pertenecer a una época muy lejana.

3. Retroceder hasta una época pasada.

Portugués:

TIND: $\quad$ 1. Remonta a águia às alturas.

2. Esta igreja remonta ao século XII.

3. O bistoriador remontou à época pré-bistórica.

PRON: 1. Remonta-se a águia às alturas.

2. Esta igreja se remonta ao século XII.

3. O bistoriador remontou-se à época pré-histórica.

Español:

PRON: $\quad$ 1. El caza se remontó a 3.000 pies de altura.

2. Esta iglesia se remonta al siglo XII.

3. El historiador se remonta a la época prehistórica.

Conforme se observa en las acepciones anteriormente citadas como ejemplo, los verbos cruzar y remontar exigen complementación indirecta o prepositiva tanto en portugués como en español. La principal diferencia estriba en que este complemento puede darse en portugués de forma no-pronominal y también pronominal, en cambio en español, esta alternancia es imposible, pues ambos verbos cruzar y remontar en estos contextos, solamente admiten el objeto indirecto con el pronombre reflexivo:

* Cruzó con ella en la calle.

* El águila remonta a las alturas.

* Esta iglesia remonta al siglo XII.

* El bistoriador remonta a la época romana.

Con respecto a los casos anteriores, conviene resaltar que, según parece, la mayoría de los verbos que generalmente rigen complementación preposicional en español lo hacen de forma pronominal. De los que se emplean con más frecuencia, Martínez 
García (1986, p. 185-190) registra un 57,49\% de verbos que se construyen con objeto indirecto pronominal frente a un $42,51 \%$ con objeto indirecto no-pronominal.

En su artículo sobre los verbos de incrementación pronominal obligatoria, Hernández Terrés (1984) ofrece como objeto de análisis específicamente los verbos que se construyen con complementos regidos pronominales cuya estructura funcional mínima de $\mathrm{V}+S E+\mathrm{S}$. Prep. se muestra "como una constante en el funcionamiento de la lengua; es el caso de verbos como 'abstenerse de', 'enterarse de', 'jactarse de', 'acordarse de', etc." (HERNÁNDEZ TERRÉS, 1984, p. 137). El autor llama la atención para el hecho de que, en contraste con el carácter vacilante que presentan otros verbos en relación con la presencia o ausencia del pronombre reflejo, hay una serie de verbos como los anteriores que destacan por la fijación de su distribución pronominal en las distintas personas, a saber, yome, tu-te, él-se, etc. Partiendo de una base léxico-verbal, propone tres criterios de clasificación formal para estos verbos:

1. Obligatoriedad de la construcción pronominal; i.e. no alternancia con otras formas en las que los mismos verbos aparecen sin pronombres.

2. Correferencialidad entre el sujeto y la persona pronominal.

3. Régimen preposicional obligatorio, ("suplemento" en la terminología del profesor Alarcos), en caso de aparecer complementada objetivamente la construcción: "acordarse $d e$ ", “quejarse de", etc. (HERNÁNDEZ TERRÉS, 1984, p. 144)

En este sistema léxico-verbal resulta importante la fijación de un contenido medio o típico de la voz media mediante la construcción con pronombre cuya presencia y unión perfecta con el lexema verbal refleja la instigación o voluntariedad del sujeto en el proceso expresado por el verbo en un contexto semántico de afección interna. En ese sentido, se puede afirmar que el pronombre en estos casos no posee una función sintáctica como comúnmente se le atribuye, sino que constituye una marca o índice 
de voz media que sirve sobre todo para concentrar los procesos significados por el verbo en el sujeto que pasa a ser la sede de forma permanente. Esta opinión es compartida por Hernández cuando trata de los verbos que exigen complemento indirecto o regido de preposición marcado de forma fija por el pronombre:

En cuanto a la posibilidad de considerar una voz media en estos casos, creemos que esto estaría más cerca de nuestro planteamiento. Efectivamente, si existen en nuestra lengua procedimientos diferentes para marcar la no-actividad y la no-pasividad por medio de usos pronominales, hay que valorar muy particularmente el que sea precisamente en los verbos que nosotros hemos delimitado, donde nuestra lengua ofrece un sistema fijo y estable que cumple esta función. Así como resulta dudoso para algunos la existencia de la voz pasiva como categoría diferenciada de nuestra lengua, no parece demasiado aventurado concluir que, si es acertado el rasgo de contenido asignado a la forma pronominal en el grupo de verbos que analizamos, dada su fijeza y no opcionalidad, i.e. su carácter estable como forma de contenido, nos encontramos con un auténtico morfema de voz media (HERNÁNDEZ TERRÉS, 1984, p. 147)

\subsection{Portugués TIND-INT Y PRON $>$ español PRON}

Del mismo modo, en contraposición a sus homólogos en español, ciertos verbos en portugués pueden acompañarse de un complemento preposicional (transitividad indirecta) o prescindir de él (intransitividad) de manera pronominal o no. Por ejemplo, el verbo apear significando "bajar a alguien de un vehículo o de una caballería" se emplea como transitivo tanto en portugués como en español:

Apeou-o do cavalo.

Nunca llegaron a Sevilla, porque un revisor los apeó del tren.

(L. CANTERO, Int , 25/8/82, p. 96 apud SECO ET AL., 1999) 
Cuando pasa a significar "bajarse alguien de un vehículo o de una caballería" el verbo apear cambia, en este caso, de una estructura transitiva a una estructura transitiva indirecta y/o intransitiva que se presenta tanto de forma no-pronominal como pronominal en portugués y exclusivamente como pronominal en castellano:

\section{Apear}

Bajarse alguien de un vehículo o de una caballería.

Portugués:

TIND: $\quad$ As damas apearam da carruagem.

O vaqueiro apeou do seu alazão.

INT: Ovaqueiro apeou.

PRON: $\quad$ Em casa, porém, apeando-me do carro...

(M. ASSIS, Brás Cubas, p. 366 apud FERNANDES, 1989)

O vaqueiro apeia-se do cavalo.

Español:

PRON: $\quad$ Es peligroso apearse de un tren en marcha.

El jinete se apeó de su brioso corcel.

El jinete se apea.

Conforme se observa, en el contexto señalado, en portugués, el verbo apear admite las construcciones transitiva indirecta e intransitiva con o sin el pronombre reflexivo, circunstancia imposible en español:

*El jinete apeó de su brioso corcel

\subsection{Portugués Int y PRon > español pron}

Algunos verbos en construcción intransitiva en español con frecuencia rechazan el empleo en voz activa asumiendo en su lugar el valor medio, contrastando de este modo con sus homólogos en portugués, que pueden variar entre los empleos de voz activa y media, llegando muchas veces a optar por la primera. En su mayoría proceden de una base estructural transitiva: 
Apagar

Dejar de arder o lucir.

Portugués:

TD: A chuva apagou a fogueira.

INT: Afogueira apagou.

PRON: Afogueira apagou-se.

Español:

TD: $\quad$ La lluvia ba apagado la boguera.

PRON: $\quad$ La boguera se ba apagado.

Dispersar

Dividirse algo colectivo o plural de modo que sus componentes queden separados.

Portugués:

TD: $\quad$ Opastor dispersou as ovelhas.

INT: As ovelhas dispersaram.

PRON: $\quad$ As ovelhas se dispersaram.

Español:

TD: $\quad$ El pastor ba dispersado a las ovejas.

PRON: $\quad$ Las ovejas se dispersaron.

Entristecer

Poner(se) triste alguien.

Portugués:

TD: $\quad$ Naquele dia, porém, a manifestação do pai foi tamanba, que a entristeceu grandemente. (M. ASSIS, Brás Cubas, p. 310 apud FERNANDES, 1989)

INT: $\quad$ Ansiavam pela bora da escola, e entristeciam ao terminar o turno das aulas. (JUCÁ, Crepúsculo, p. 108 apud FERNANDES, 1989)

PRON: $\quad$ Opastor, quando uma ovelba lbe morre, lá se entristece. (Pe. Teodoro Almeida, Feliz Independente, II, p. 91 apud FERNANDES, 1989)

Español:

TD:

Cuando niña, yo esperaba alegre la primera nevada .. Las otras nevadas, a lo largo del invierno, me entristecían. (CUNQUEIRO, Rev 1.71, p. 31 apud SECO ET AL., 1999) 
PRON: $\quad$ ¿Quién es el guapo que se entristece cuando el sol lo inunda todo y cuando cada árbol se convierte en una sala de conciertos donde actúa un orfeón de pájaros? (LAIGLEISA, Tachado, p. 187 apud SECO ET AL., 1999)

Pegar

Pasar algo, especialmente una enfermedad o una cualidad a alguien por trato o por contacto con otros.

Portugués:

TDI:

Pegou a doença ao (ou no) irmão.

Pegou parotidite da (ou na) namorada.

INT: $\quad$ Uma gripe que pega facilmente. (HOUAISS, 2002)

Esse mal pega?

PRON: $\quad$ Uma gripe que se pega facilmente. (HOUAISS, 2002)

Esse mal se pega?

Español:

TDI:

En el pueblo me habian dicho que ir de prostitutas era inmoral y que te podían pegar una enfermedad incurable. (S. PAÍS 24/6/79, p. 21 apud SECO ET AL., 1999)

PRON: $\quad$ No tengas aprensión, que la sinusitis no se pega. (SECO ET AL., 1999)

En los cuatro ejemplos anteriores se observa que tanto en portugués como en español los verbos apagar, dispersar, entristecer y pegar, en las acepciones que se ofrecen, se emplean como transitivos (o bitransitivos). Pero en portugués el empleo intransitivo de los mismos puede darse de forma no pronominal y pronominal, al tiempo que en español la intransitividad, en este caso, solo es posible mediante la pronominalización.

En todos los ejemplos anteriores, constatamos que los verbos en cuestión poseen en portugués la facultad de poder emplearse tanto como transitivos indirectos como intransitivos, sin que para ello tengan que recurrir necesariamente al recurso de la pronominalización como sucede en español, por lo que pueden alternar libremente entre los esquemas de verbo transitivo indirecto o intransitivo de forma no-pronominal (TIND O INT) o de forma pronominal (PTIND O PIN). Por otra parte, esta doble posibilidad de uso a menudo conlleva que uno de los modelos 
sea más fuerte que el otro, aunque la lengua admita ambos, de ahí que algunos verbos intransitivos en portugués se empleen más frecuentemente en el modelo no-pronominal y rara vez en el pronominal en determinados contextos en los que se emplean exclusivamente como pronominales en español:

Afogar /abogar

Inundarse el carburador por exceso de combustible.

Portugués:

INT: $\quad$ O motor morre, afoga,$^{2}$ a suspensão faz barulbo etc. (Corpus NILC/São Carlos)

Español:

PRON: $\quad$ Al acelerar el motor se aboga. (RAMOS-L. SERRANO, Circulación, p. 122 apud SECO ET AL., 1999)

Adormecer

Entrar en estado de somnolencia o sueño ligero.

Portugués:

INT:

A garota adormeceu.

Español:

PRON: $\quad$ Vamos a curiosear en la cubierta, donde se adormecen los marineros de guardia, donde también dormita, arrimado a un calabrote, un petimetre. (TORRENTE, Isla, p. 108 apud SECO ET AL., 1999)

Marchitar

Ponerse marchito.

Portugués:

INT: $\quad$ Cortadas, rapidamente murcham as flores. (LUFT, 1987) As rosas que ganbou murcharam logo. (HOUAISS, 2002)

${ }^{2}$ No obstante, el uso pronominal de afogar es obligatorio en portugués al igual que en español cuando se refiere, por ejemplo, a "morir por asfixia al quedar sumergido en el agua": Ele se afogou quando as águas invadiram o barraco em que dormia, às $5 b$ de ontem. (Corpus: NILC/São Carlos) / Desde que enviudó al abogarse su marido en el caz había hecho su capricho. (SAMPEDRO, Sonrisa, p. 261 apud SECO ET AL., 1999). 
Español:

PRON: $\quad$ Las flores, más que otra parte cualquiera de la planta, son delicadas: se marchitan y pasan pronto. (Economía, 304 apud SECO ET AL., 1999)

Serenar

Pasar alguien o algo a estar sereno.

Portugués:

INT: $\quad$ Exaltei-me, mas depois serenei. (HOUAISS, 2002)

Serenaram os operários ouvindo o líder. (LUFT, 1987)

Español:

PRON: $\quad$ Estuvo llorando un buen rato, pero después se serenó.

En algunas ocasiones, el empleo pronominal de estos verbos en portugués denota más bien un deseo de poner de relieve la afectividad del sujeto, la expresividad de la acción, como ocurre, por ejemplo, con el verbo rir ("reír") que casi nunca aparece en portugués en la forma pronominal, siendo más normal y frecuente en los esquemas no-pronominales INT (intransitivo) $O$ TIND (transitivo indirecto) (LUFT, 1987, p. 12):

Irene ri (da gafe cometida pelo colega).

Si se le añade en este caso el pronombre reflexivo, se le quiere dar mayor énfasis a la expresividad de la acción realizada por el sujeto:

Irene se ri (da gafe contada pelo colega).

En español, como en portugués, el verbo reír igualmente alterna el uso intransitivo con el uso pronominal:

Al oír las quejas de sus caballeros, ríe, ríe, ríe la divina Eulalia."

(RUBÉN DARÍO, Prosas profanas)

Natalia empieza a sonreír. Se ríe. Suelta la carcajada.

(MEDIO, Bibiana, p. 116 apud SECO ET AL., 1999)

Sin embargo, repárese que a diferencia de lo que sucede en portugués, en español, reír no admite el régimen transitivo 
indirecto (TIND), pues al llevar un complemento preposicional se convierte necesariamente en verbo pronominal:

Nadie se rió del chiste. / Nadie rió del chiste.

El verbo ir es otro ejemplo interesante de los entresijos que guarda la dicotomía no-pronominal/pronominal de las lenguas portuguesa y española. Este verbo cuando se usa en el sentido de "abandonar una persona el sitio en que está", especialmente si se refiere a una marcha definitiva, en portugués casi siempre ocurre lexicalizado mediante el adverbio embora, cuyo significado de origen se ha perdido por completo en la lengua actual. De esta forma suele emplearse tanto de forma no-pronominal como pronominal:

Ele foi embora e nem se despediu de mim.

Ele foi-se embora e nem se despediu de mim.

Sin embargo si se prescinde en el contexto de su forma lexicalizada no suele admitir empleo no-pronominal:

Ele foi-se e nem se despediu de mim.

*Ele foi e nem se despediu de mim.

Similarmente a este último caso, en español el verbo ir no admite alternancia en este contexto, empleándose siempre como pronominal:

Nosotros también tendríamos una obligación y, sin embargo, nos íbamos. (HOYO, Pequeñuelo, p. 11, apud SECO ET AL., 1999) Se fue y no volvió.

Conforme se ha visto, casi todos los verbos estudiados hasta el momento presentan mayor predisposición al uso intransitivo o transitivo indirecto no-pronominal en portugués, en contraposición al uso pronominal único en castellano. Por otra parte, de modo general, se observa en portugués cierta tendencia a la transitivización indirecta o intransitivización no pronominal que afecta incluso a verbos tradicionalmente empleados como pronominales, a través de la supresión del pronombre reflejo, conforme constatamos en los ejemplos: 
A sociedade cansou de pagar impostos, porque eles recaem injustamente sobre os pobres mais do que sobre os ricos. (Corpus NILC / São Carlos)

O empresário Augusto Morbach Neto casou com Selma Silva no último sábado em cerimônia no fórum de Belém. (Corpus NILC / São Carlos) Maura vê Celso piscando a luz da sala para ela ir encontrar com ele. (FOLHAONLINE, Ilustrada, 11/04/2006)

Fui para a Costa do Sauípe (BA), relaxei e descansei bastante, coloquei os pés para cima. (FOLHAONLINE, Esporte, 13/09/2004)

Sin embargo, esta pérdida del pronombre reflejo verificable en los ejemplos anteriores de verbos en portugués no se da con sus correspondientes verbos en español cuyo empleo pronominal se presenta de forma fija:

Demi Moore se ha casado con Ashton Kutcher. (Revista iHOLA!, $6 / 10 / 05$, noticia de portada)

Me be cansado de escuchar siempre lo mismo.

He quedado de encontrarme con Juan.

Después de descargar adrenalina haciendo deporte, lo bueno es volver a casa y relajarse. (Elmundo.es, Compras, 13/01/2006)

\section{Consideraciones finales}

Los cambios de régimen transitivo, intransitivo y pronominal se relacionan de modo directo, puesto que la intransitivización de los verbos transitivos suele ir acompañada, a su vez, de un proceso de pronominalización: El público abarrotaba el teatro / El teatro se abarrotaba de público. El español rentabiliza en gran medida este uso latino de la voz media, de modo que la mayoría de los verbos transitivos se pronominalizan a la vez que se intransitivizan. Por esa razón, ciertos verbos en portugués difieren marcadamente de sus equivalentes en español, pues, en contraste con estos, no se convierten necesariamente en pronominales al adoptar una estructura intransitiva o transitiva indirecta, sino que, en la mayoría de las veces, alternan con enorme facilidad entre el empleo intransitivo o transitivo indirecto nopronominal y pronominal, llegando, en ocasiones, a preferir el 
uso no-pronominal, lo que apunta a una progresiva pérdida del pronombre reflexivo.

Se ha podido constatar la existencia de verbos en español que tienden a una fijación pronominal en contextos que denotan el valor de afección interna de sujeto, que se presenta enormemente instigado en el proceso verbal. De ello se desprende que el pronombre en estos casos, más que un morfema verbal con función sintáctico-semántica, constituye un verdadero signo o marca de presencia de voz media como un rasgo de contenido atribuido al verbo de forma permanente.

\section{Referencias}

CORPUS: NILC/São Carlos, Acesso a corpora de português: Projeto AC/ DC, [Disponible en http://www.linguateca/pt/CETENFolha].

FERNANDES, F. Dicionário de verbos e regimes. 36. ed. Rio de Janeiro: Globo, 1989.

HERNÁNDEZ, C. Gramática funcional del español. 2. ed. Madrid: Gredos, 1986.

HERNÁNDEZ TERRÉS, J. M. Un tipo de construcciones pronominales en español: los verbos con incrementación pronominal obligatoria. ELUA: Estudios de Lingüística Universidad Alicante, Alicante, n. 2, p. 137-153, 1984.

HOUAISS, A. Dicionário eletrônico Houaiss da língua portuguesa. Rio de Janeiro: Objetiva, 2002.

LUFT, C. P. Dicionário prático de regência verbal. São Paulo: Ática, 1987.

MARTÍN ZORRAQUINO, M. A. Las construcciones pronominales en español: paradigma y desviacion. Madrid: Gredos, 1979.

MARTÍNEZ GARCÍA, H. El suplemento en español. Madrid: Gredos, 1986.

PENA, J. La voz en español: intento de caracterización. Verba, Santiago de Compostela, n. 9, p. 215-252, 1982. 
PEREIRA, S. de S. Estudio contrastivo del régimen verbal en el portugués de Brasil y el español peninsular. Tesis (Doctorado en Lingüística General) - Universidade de Santiago de Compostela, Santiago de Compostela, 2007.

SECO, M. et al. Diccionario del español actual, Madrid: Aguilar Lexicografía, Grupo Santillana de Ediciones, 1999. 2 vol. (I: A-F; II: G-Z).

Recebido para publicação em 31 de agosto de 2012 Aprovado em 3 de novembro de 2012 